\title{
MITRA-FR: speed bump or end of the road for percutaneous mitral repair in secondary mitral regurgitation?
}

\author{
2 \\ Darren Mylotte, MB BCh, MD, Deputy Editor
}

The last decade has seen a steady stream of successful clinical trial data for structural heart interventions. Transcatheter aortic valve implantation is of course the poster child, but pulmonary valve implantation, left atrial appendage occlusion, and patent foramen ovale closure have been established as safe and efficacious therapies. The publication in the current edition of EuroIntervention of the first series of patients successfully undergoing percutaneous closure of sinus venosus atrial septal defects further illustrates the current capabilities and future potential of the structural field ${ }^{1}$.

\section{Article, see page 868}

The Monday Hotline session at the annual congress of the European Society of Cardiology in Munich, however, delivered a sobering rebuke to those involved in the field of percutaneous mitral valve repair or replacement.

MITRA-FR is the first study to compare percutaneous mitral valve repair with the MitraClip ${ }^{\circledR}$ MC device (Abbott Vascular, Santa Clara, CA, USA) and optimal medical therapy $(n=152)$ to optimal therapy alone $(n=152)$ among patients with symptomatic heart failure, reduced left ventricular ejection fraction (LVEF), and severe secondary mitral regurgitation $(\mathrm{MR})^{2}$. As has been widely reported, and discussed in cath labs and operating rooms worldwide, the primary efficacy outcome, a composite of death from any cause or unplanned hospitalisation for heart failure at one year, occurred at a similar rate in both groups (odds ratio [OR] $1.16,95 \%$ confidence interval $[\mathrm{CI}]: 0.73-1.84 ; \mathrm{p}=0.53$ ).

To many, these results were unexpected. Among patients with heart failure with reduced LVEF, severe secondary MR is associated with a poor prognosis $(50 \% \text { mortality at five years })^{3}$. The greater the MR severity, the more symptomatic the patient, and the higher the mortality rate. Percutaneous repair successfully reduces secondary $\mathrm{MR}^{4}$, so, intuitively, eliminating the MR should improve quality of life and reduce mortality - right?

Well, maybe not. Secondary MR is not a disease of the mitral apparatus but is usually a disease of the left ventricle (LV): maladaptive LV remodelling causes deformation of the normal mitral valve apparatus and leads to incomplete closure of the mitral valve leaflets. Optimal medical therapy, including cardiac resynchronisation, is considered to be the standard of care for secondary MR and has been shown to reduce MR severity ${ }^{5}$. The role of surgery for secondary MR in heart failure patients remains controversial. Randomised trials of surgical repair of moderate ischaemic MR during concomitant coronary artery bypass grafting (CABG) have not demonstrated benefit compared with $\mathrm{CABG}$ alone ${ }^{6}$. Hence, current guidelines only recommend addressing severe secondary MR during concomitant CABG or in severely symptomatic patients at low surgical risk failing optimal medical therapy ${ }^{7}$. Importantly, these recommendations are based on expert consensus with a $\mathrm{C}$ grade level of evidence ${ }^{7}$.

So, what about the MITRA-FR study? This is the first study to randomise percutaneous mitral repair to optimal medical therapy. The study was expertly performed, but there are some features of the trial worthy of discussion: 1) It is a small study, enrolling only 152 patients in each arm, and powered to detect a $17 \%$ absolute reduction in the rate of the primary efficacy outcome (all-cause death and rehospitalisation). More modest differences in effect size may not be detected in such a small study. Moreover, 48 out of 152 patients in the intervention arm $(31.6 \%)$ did not meet the enrolment criteria, did not receive the device, or deviated from the study protocol. 2) In the words of the authors, "A large amount of follow-up data on echocardiographic outcomes, functional status, natriuretic peptide levels, and quality-of-life outcomes at one year were missing. As a consequence, the results are subject to substantial selection bias, and no formal statistical analyses are reported". While there is no question about the integrity of the adjudication of the primary efficacy endpoint, large volumes of missing data do raise concerns and make interpretation of secondary endpoints in particular very difficult. 3) In $10 \%$ of patients in the intervention arm, the MitraClip was not implanted, $14.1 \%$ suffered serious periprocedural complications and, on hospital discharge, $25 \%$ had MR $\geq$ grade 2 . Procedural success with the device was similar 
to previous studies, but among patients fulfilling the criteria for procedural success and with echocardiographic data available at 12 months $(n=97)$, nearly half $(n=48)$ had residual MR $\geq$ grade 2 . This study captures the very early experience of the now redundant MitraClip MC device in French centres relatively new to the technology. The current MitraClip (NTR and XTR) is more userfriendly with enhanced manoeuvrability and more efficient leaflet grasping. 4) Most importantly, patients included in MITRA-FR had advanced heart failure (New York Heart Association [NYHA] Class III/IV >60\%/mean LVEF: $33 \%$ /cardiac resynchronisation $>25 \%$ ) and may well have been too late in their disease course to derive a benefit from treatment of MR. Supporting this hypothesis, a recent longitudinal study has suggested that severe secondary MR is only a predictor of adverse outcome in an "intermediate" heart failure phenotype (NYHA Class II/III and moderately reduced LVEF) ${ }^{3}$. In more advanced heart failure, severe secondary MR is not associated with long-term mortality. Whether MitraClip would have been more efficacious in a less advanced heart failure population is the subject of ongoing evaluation. 5) At baseline, medical therapy was documented and was universally excellent (beta-blockers 90\%; ACE inhibition 74\%; mineralocorticoid receptor antagonists 55\%). However, it is unknown if these therapies were maintained and whether between-group differences emerged during follow-up as these data were not captured. The similar improvement in NYHA class observed in both treatment arms suggests that medical therapy may have been further optimised in the control group. 6) The follow-up period of 12 months may be too short to allow a benefit from MR reduction to accrue.

The investigators of MITRA-FR should be congratulated for executing a difficult study in a challenging patient population. This study reminds us of the importance of guideline-directed optimal medical therapy in advanced heart failure patients. Percutaneous repair of secondary MR is not a panacea, does not appear to be effective in this advanced heart failure population, and may only be of benefit in specific patient subgroups or during a therapeutic window where early repair can reverse the otherwise progressive LV remodelling. Thankfully, we do not have to wait too long for the results of the Clinical Outcomes Assessment of the MitraClip Percutaneous Therapy for Heart Failure Patients With Functional Mitral Regurgitation (COAPT) trial (NCT01626079) which has randomised 614 patients with secondary MR and heart failure to MitraClip or medical therapy in the United States. This patient population has more severe MR and less advanced heart failure than that in MITRA-FR. The primary efficacy endpoint in COAPT is recurrent heart failure hospitalisation (not paired with mortality as in MITRA-FR). The results will be presented at TCT 2018, San Diego, CA, USA. The larger Randomized Study of the MitraClip Device in Heart Failure Patients With Clinically Significant Functional Mitral Regurgitation (RESHAPE-HF) trial (NCT01772108) will randomise 800 patients in a similar fashion.

So, does MITRA-FR represent the end of the road for the percutaneous treatment of secondary MR or does it simply represent a speed bump along the development pathway of this innovative technology? Time will tell...

\section{References}

1. Riahi M, Velasco Forte MN, Byrne N, Hermuzi A, Jones M, Baruteau AE, Valverde I, Qureshi SA, Rosenthal E. Early experience of transcatheter correction of superior sinus venosus atrial septal defect with partial anomalous pulmonary venous drainage. EuroIntervention. 2018;14:868-76.

2. Obadia JF, Messika-Zeitoun D, Leurent G, Iung B, Bonnet G, Piriou N, Lefèvre T, Piot C, Rouleau F, Carrié D, Nejjari M, Ohlmann P, Leclercq F, Saint Etienne C, Teiger E, Leroux L, Karam N, Michel N, Gilard M, Donal E, Trochu JN, Cormier B, Armoiry X, Boutitie F, Maucort-Boulch D, Barnel C, Samson G, Guerin P, Vahanian A, Mewton N; MITRA-FR Investigators. Percutaneous Repair or Medical Treatment for Secondary Mitral Regurgitation. N Engl J Med. 2018 Aug 27. [Epub ahead of print].

3. Goliasch G, Bartko PE, Pavo N, Neuhold S, Wurm R, Mascherbauer J, Lang IM, Strunk G, Hülsmann M. Refining the prognostic impact of functional mitral regurgitation in chronic heart failure. Eur Heart J. 2018;39:39-46.

4. Schueler R, Nickenig G, May AE, Schillinger W, Bekeredjian R, Ouarrak T, Schofer J, Hehrlein C, Sievert H, Boekstegers P, Lubos E, Hoffmann R, Baldus S, Senges J, Hammerstingl C. Predictors for short-term outcomes of patients undergoing transcatheter mitral valve interventions: analysis of 778 prospective patients from the German TRAMI registry focusing on baseline renal function. EuroIntervention. 2016;12:508-14.

5. Weiner RB, Baggish AL, Chen-Tournoux A, Marshall JE, Gaggin HK, Bhardwaj A, Mohammed AA, Rehman SU, Barajas L, Barajas J, Gregory SA, Moore SA, Semigran MJ, Januzzi JL Jr. Improvement in structural and functional echocardiographic parameters during chronic heart failure therapy guided by natriuretic peptides: mechanistic insights from the ProBNP Outpatient Tailored Chronic Heart Failure (PROTECT) study. Eur J Heart Fail. 2013;15:342-51.

6. Michler RE, Smith PK, Parides MK, Ailawadi G, Thourani V, Moskowitz AJ, Acker MA, Hung JW, Chang HL, Perrault LP, Gillinov AM, Argenziano M, Bagiella E, Overbey JR, Moquete EG, Gupta LN, Miller MA, Taddei-Peters WC, Jeffries N, Weisel RD, Rose EA, Gammie JS, DeRose JJ Jr, Puskas JD, Dagenais F, Burks SG, El-Hamamsy I, Milano CA, Atluri P, Voisine P, O'Gara PT, Gelijns AC; CTSN. Two-Year Outcomes of Surgical Treatment of Moderate Ischemic Mitral Regurgitation. $N$ Engl J Med. 2016;374:1932-41.

7. Baumgartner H, Falk V, Bax JJ, De Bonis M, Hamm C, Holm PJ, Iung B, Lancellotti P, Lansac E, Rodriguez Munoz D, Rosenhek R, Sjogren J, Tornos Mas P, Vahanian A, Walther T, Wendler O, Windecker S, Zamorano JL; ESC Scientific Document Group. 2017 ESC/EACTS Guidelines for the management of valvular heart disease. Eur Heart J. 2017;38:2739-91. 